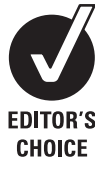

${ }^{1}$ Cincinnati Children's Hospital Research Foundation Sports Medicine Biodynamics Center and Human Performance Laboratory, Cincinnati, Ohio, USA; ${ }^{2}$ University of Toledo, Engineering Center for Orthopaedic Research Excellence, Toledo, Ohio, USA; ${ }^{3}$ Cincinnati Children's Hospital Research Foundation, Division of Molecular Cardiovascular Biology Cincinnati, Ohio, USA;

${ }^{4}$ University of Cincinnati College of Medicine, Departments of Pediatrics, Orthopaedic, Surgery Biomedical Engineering, and Department of Rehabilitation Sciences, College of Allied Health Sciences, Cincinnati, Ohio, USA

Correspondence to: Dr T E Hewett, Cincinnati Children's Hospital, 3333 Burnet Avenue; MLC 10001, Cincinnati, OH 45229, USA; tim.hewett@ cchmc.org

Accepted 8 April 2009 Published Online First 15 April 2009

\title{
The anterior cruciate ligament injury controversy: is "valgus collapse" a sex-specific mechanism?
}

\author{
C E Quatman, ${ }^{1,2}$ T E Hewett ${ }^{1,3,4}$
}

\begin{abstract}
Background: Anterior cruciate ligament (ACL) injury is a devastating injury that puts an athlete at high risk of future osteoarthritis. Identification of risk factors and development of ACL prevention programmes likely decrease injury risk. Although studies indicate that sagittal plane biomechanical factors contribute to ACL loading mechanisms, it is unlikely that non-contact ACL injuries occur solely in a sagittal plane. Some authors attempt to ascribe the solely sagittal plane injury mechanism to both female and male ACL injuries and rebuff the concept that knee "valgus" is associated with isolated ACL injury. Prospective studies that utilise coupled biomechanical and epidemiological approaches demonstrated that frontal knee motions and torques are strong predictors of future non-contact $\mathrm{ACL}$ injury risk in female athletes. Video analysis studies also indicate a frontal plane "valgus collapse" mechanism of injury in women. As load sharing between knee ligaments is complex, frontal as well as sagittal and transverse plane loading mechanisms likely contribute to non-contact $A C L$ injury. The purpose of this review is to summarise existing evidence regarding $\mathrm{ACL}$ injury mechanisms and to propose that sex-specific mechanisms of ACL injury may occur, with women sustaining injuries by a predominantly "valgus collapse" mechanism.
\end{abstract}

Conclusion: Prevention programmes and interventions that only target high-risk sagittal plane landing mechanics, especially in the female athlete, are likely to be less effective in ameliorating important frontal and transverse plane contributions to $\mathrm{ACL}$ injury mechanisms and could seriously hamper ACL injury prevention efforts.

Programmes that target the reduction of high-risk valgus and sagittal plane movements will probably prove to be superior for ACL injury prevention.

Anterior cruciate ligament (ACL) injuries place an athlete at greatly increased risk of developing knee osteoarthritis later in life. In addition to knee pain and instability, ACL injury may cause a substantial financial burden and lead to long-term disability for young athletes. Using a conservative cost of US\$17 000 per patient for surgery and rehabilitation, the estimated cost for treatment in ACLinjured patients in the USA is over 1.7 billion dollars annually. ${ }^{2}$ Although many advances have been made in terms of surgical and rehabilitation interventions for ACL-injured patients, long-term outcome studies show that these patients are at a high risk of developing osteoarthritis $10-15$ years after ACL injury, regardless of the treatment. ${ }^{3-5}$ Identification of high-risk manoeuvres that lead to ACL injury would aid in the development of neuromuscular training programmes targeted at decreasing dangerous knee loading patterns and preventing ACL injury.
It is well established that women have a higher risk of ACL injury, and ACL studies have often focused on the determination of differences between the sexes that may increase a female athlete's risk of injury. ${ }^{67}$ Whereas anatomical, hormonal and neuromuscular differences may be observed between the sexes, ${ }^{8}$ it remains a challenge to correlate what is studied in the laboratory setting to what actually occurs during an ACL injury event, and it may not follow that these sex differences are the underlying cause of increased ACL injury risk in women. There is even evidence to indicate that women may injure their ACL by an entirely different mechanism than men. ${ }^{9}{ }^{10}$

\section{WHAT IS THE INCITING EVENT IN NON-CONTACT ACL INJURY?}

A great deal of controversy and current research surrounds the inciting event and the biomechanical mechanisms underlying non-contact ACL injury. Whereas the intrinsic and extrinsic risk factors for ACL injury have been explored extensively, the factors surrounding the inciting event and the biomechanical mechanisms underlying non-contact ACL injury require greater analysis. Methods to describe ACL loading and injury mechanisms have included athlete interviews, in-vivo arthroscopic, clinical, video analysis, cadaveric, motion analysis, electromyographic and mathematical modelling studies. However, these studies have provided contradictory and inconclusive results and thus widely varying interpretations as to the inciting event. ${ }^{9}$

Observational studies indicate that most noncontact ACL injuries occur during lateral pivoting, landing or deceleration manoeuvres during sports play. ${ }^{11}$ However, the planes of knee motion that lead to non-contact ACL injury are not completely clear and remain a controversial issue in the literature. Video studies of ACL injuries provide evidence that supports two predominant loading patterns: injury as a result of knee valgus collapse (a combination of knee valgus, hip internal rotation and tibial rotation) or by anterior tibial shear (although the biomechanical evaluation of anterior tibial shear by video analysis is difficult). ${ }^{9-}$ 13

The ACL provides approximately $85 \%$ of the knee joint's total restraint to anterior tibial translation at $20-30^{\circ}$ of knee flexion ${ }^{14-17}$ and as studies have shown that sagittal plane knee angles near full extension and large quadriceps muscle forces increase ACL loading, many clinicians support a predominantly sagittal plane ACL injury mechanism. ${ }^{18}$ In contrast, pure frontal (valgusvarus) or transverse (internal-external) plane knee 


\begin{tabular}{|c|c|}
\hline \multicolumn{2}{|c|}{ Multi-planar loading in women } \\
\hline \multicolumn{2}{|c|}{ Body position } \\
\hline Back & $\begin{array}{l}\text { Forward flexed, } \\
\text { rotated opposite side }\end{array}$ \\
\hline Hips & $\begin{array}{l}\text { Adduction } \\
\text { internal rotation }\end{array}$ \\
\hline Knee & Less flexed, valgus \\
\hline $\begin{array}{l}\text { Tibial } \\
\text { rotation }\end{array}$ & Internal or external \\
\hline $\begin{array}{l}\text { Landing } \\
\text { pattern }\end{array}$ & $\begin{array}{l}\text { One foot out of control } \\
\text { unbalanced }\end{array}$ \\
\hline
\end{tabular}

Figure 1 Multiplanar loading mechanism in women.

loads have a less obvious effect on ACL strain, and the MCL, not the ACL, is reportedly the primary restraint against valgus stress in the knee joint. ${ }^{14} 19$ In contrast to this accepted dogma, both in-vivo biomechanical data and video analyses indicate that increased lower extremity valgus loads and movements in the frontal plane are probably associated with an increased risk of ACL injury. ${ }^{11} 2021$ Although the ACL may be subject to large forces during various loading conditions, ${ }^{22}$ load sharing among knee joint ligaments is complex and there is strong evidence that non-contact ACL injuries likely occur as a result of increased motion and loading in the sagittal, frontal, transverse and/or multiplanar conditions. $.^{9-11} 22-27$ The purpose of this review is to highlight the evidence for a frontal plane ("valgus collapse") mechanism, because of its important implications for relative risk prediction and ACL intervention programmes.

\section{VALGUS COLLAPSE MECHANISM: A MORE RECENT DISCOVERY AND PROBABLE MECHANISM OF INJURY IN WOMEN}

"Valgus" refers to the outward angulation of the distal segment of a bone or joint. At the knee joint, valgus may occur from a pure abduction motion of the distal tibia relative to the femur or from transverse plane knee rotation motions (femoral/tibial internal and external rotations). Hollis and colleagues ${ }^{28}$ described the axial rotation of the tibia relative to the femur during a "valgus" load application and found that at increasing knee flexion angles, the internal tibial rotation increased with a maximum of up to $21^{\circ}$ of rotation at $90^{\circ}$ of flexion. Therefore, describing an injury mechanism as a valgus collapse does not necessarily indicate that the injury occurs solely in the frontal plane and contributions of other planar movements should also be considered.

\section{Typical postures at the time of ACL injury}

Non-contact ACL injuries often exhibit a common body posture that involves a valgus collapse of the knee joint, with the knee near full extension (between $0^{\circ}$ and $30^{\circ}$ ), external tibial rotation with the foot planted during a deceleration manoeuvre. ${ }^{911}$ Video studies by Olsen et $a l^{21}$ and Krosshaug et $a l^{9}$ found that

\begin{tabular}{|l|l|}
\hline \multicolumn{2}{|c|}{ Sagittal plane loading in men } \\
\hline \multicolumn{1}{|c|}{ Body position } \\
\hline Back & $\begin{array}{l}\text { Upright } \\
\text { not rotated }\end{array}$ \\
\hline Hips & $\begin{array}{l}\text { Neutral } \\
\text { little adduction/ } \\
\text { rotation }\end{array}$ \\
Knee & $\begin{array}{l}\text { More flexed } \\
\text { less valgus } \\
\text { Tibial } \\
\text { rotation }\end{array}$ \\
$\begin{array}{l}\text { Minimal } \\
\text { Landing } \\
\text { pattern }\end{array}$ & $\begin{array}{l}\text { Both feet in control } \\
\text { balanced }\end{array}$ \\
\hline
\end{tabular}

Figure 2 More sagittal plane-oriented loading mechanism in men?

dynamic valgus collapse was the most common ACL injury mechanism for female handball and basketball athletes. Krosshaug et al ${ }^{9}$ also found that female basketball players demonstrated a 5.3 times higher relative risk of valgus collapse during ACL injury compared with male basketball players.

Female athletes exhibit more knee valgus motion and torque during athletic movements than men and these altered mechanics are predictors of future ACL injury risk. ${ }^{20-32} \mathrm{We}$ prospectively screened athletes before their athletic seasons and discovered that during landing, athletes who went on to experience ACL injury had knee valgus angles more than $8^{\circ}$ greater than athletes who completed the season uninjured. Our preseason measure of dynamic valgus moments predicted ACL injury with $73 \%$ sensitivity and $78 \%$ specificity. ${ }^{20}$

It is conceivable that men and women have different primary underlying mechanisms of ACL injury, with women experiencing more injuries as a result of valgus collapse than men (figs 1 and 2). Over $50 \%$ of the women in a Norwegian handball study demonstrated a valgus knee collapse during the injury event, whereas only $20 \%$ of the men showed a similar collapse. ${ }^{9}$ A recent study by Boden et $a^{10}$ corroborated these findings, showing that women had higher valgus angles than their male counterparts during ACL injury. ${ }^{10}$ Mathematical modelling studies demonstrate that perturbations to the lower extremity during a side-step cutting manoeuvre can lead to external valgus loads that are capable of rupturing the ACL and these valgus loads occur more frequently in women than men. ${ }^{33} 34$

What additional evidence is there that valgus collapse is an important contributor to ACL injury?

Consider how clinical tests of knee stability parallel the forces that potentially occur at the knee during an inciting event. The Lachman's and anterior drawer tests indicate the importance of the ACL in restraining anterior tibial translation. Similarly, the pivot shift test (fig 3) is the most specific clinical test for ACL deficiency; it has $98 \%$ specificity (95\% CI 96 to 99). ${ }^{35}$ When comparing the relative importance of these motions, note that ACL-deficient patients can generally function well when they limit themselves to sagittal plane movements; however, rotational movements often lead to feelings of instability and 


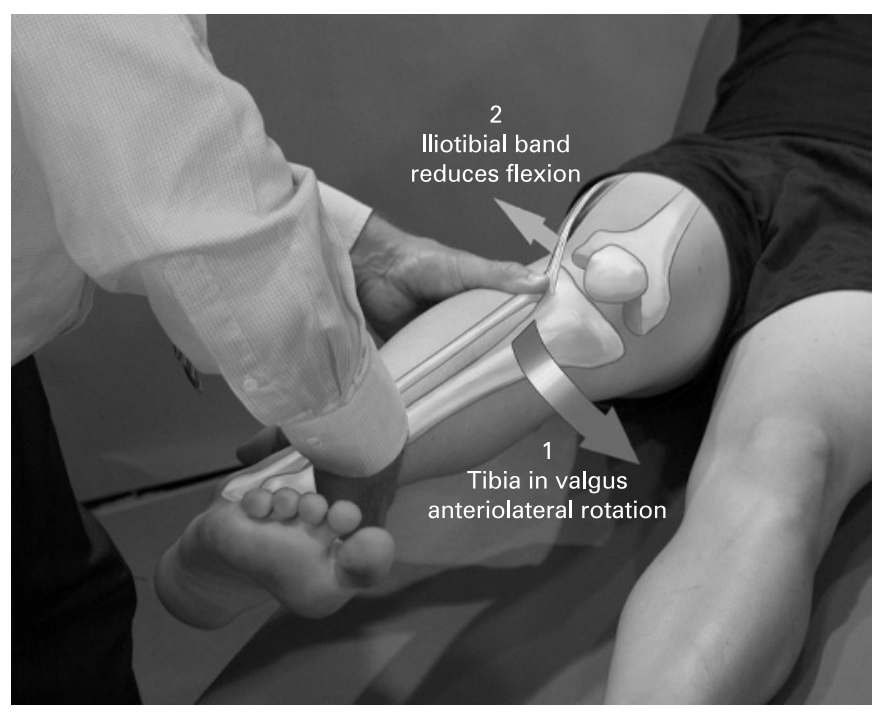

Figure 3 The pivot shift test is performed with the patient lying supine with their hip passively flexed to $30^{\circ}$. Approximately $20^{\circ}$ of internal rotation is applied to the tibia and the knee is placed in full extension. A valgus force is applied to the knee as it is slowly flexed. An anterior cruciate ligament-deficient knee will remain reduced in full extension but will sublux around $20-30^{\circ}$ of knee flexion and then will reduce again in deeper flexion.

symptomatic "giving way" episodes. The pivot shift test stresses the rotational restraint of the ACL and a large pivot shift predicts a poor outcome following injury. ${ }^{36}$ We postulate that the pivot shift probably reproduces the luxations that occur during an ACL injury.

Clinical imaging and diagnostic studies also indicate that valgus collapse probably occurs during ACL injury. Bone bruises of the lateral femoral condyle or posterolateral portions of the tibial plateau occur approximately $80 \%$ of the time in magnetic resonance imaging (MRI) studies after acute ACL injury (fig 4). ${ }^{37-40}$ Lateral tibial and femoral bone bruises associated with acute ACL injuries indicate that compression occurs laterally while the medial aspect of the joint unloads.
Posterior tibial plateau bone bruises could result from internal tibial rotation, femoral external rotation, abduction and/or anterior tibial translation.

Adding to the argument that there may be sex-specific mechanisms of injury, Fayad et $a l^{41}$ reported that women more commonly acquired posterolateral tibial bone bruises after ACL injury, whereas men had more medial meniscus, lateral collateral ligament and posterior cruciate ligament injuries. This sex difference in concomitant injuries associated with ACL ruptures is consistent with women having more valgus-driven injury mechanisms and men experiencing more sagittal planeoriented ACL injury mechanisms. As women demonstrate greater knee valgus postures and moments compared with men during jumping, landing and cutting activities, their risk of dangerous knee valgus mechanics is elevated. ${ }^{42} 43$

An underrecognised, but unmodifiable factor that may increase the risk of ACL injury as a result of valgus collapse is the slope of the posterior tibial plateau. ACL-injured patients may have greater posterior lateral tibial plateau slopes compared with controls (but not medial tibial slopes). This may predispose them to more transverse plane rotation during high-risk manoeuvres. ${ }^{44}$ Both Kujala et $a l^{45}$ and Brandon et al ${ }^{46}$ found that greater posterior tibial slopes were associated with higher pivot shift grades and an increased likelihood of experiencing symptomatic giving way episodes in ACL-deficient patients. Therefore, a large posterior tibial plateau slope combined with greater lateral femoral condylar translation on the tibia compared with the medial condyle increases the likelihood of transverse plane rotations and probably increases an individual's risk of ACL injury as a result of valgus collapse. ${ }^{47}$

Several cadaveric studies demonstrate that the ACL experiences increased force during valgus loads. ${ }^{22}{ }^{48}$ Quadriceps force coupled with a valgus load increases the ACL force up to $100 \%$ compared with valgus loads without a quadriceps force. ${ }^{22}$ Similarly, coupled valgus loading with anterior tibial force leads to higher ACL forces and strains than isolated anterior tibial force. ${ }^{48}$ Withrow et al ${ }^{49}$ demonstrated that valgus knee alignment led to $30 \%$ greater ACL strains compared with knees in neutral alignment when subjected to impulsive compression loads.
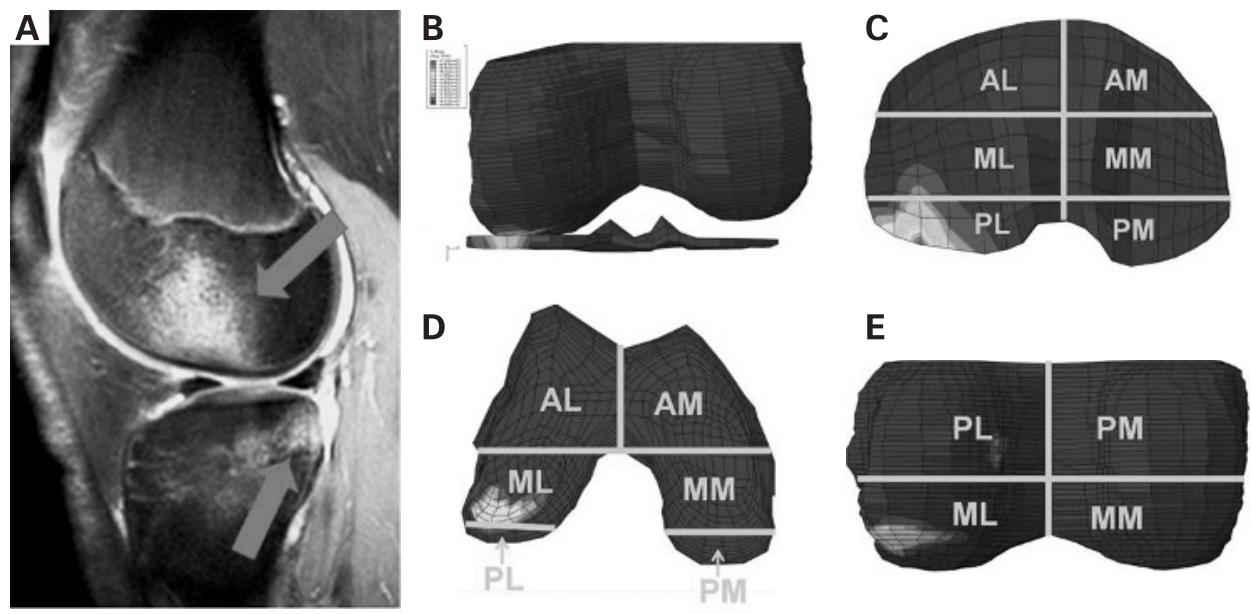

Figure 4 (A) Magnetic resonance imaging of bone bruise pattern (lateral femoral condyle and posterolateral tibial plateau) associated with acute anterior cruciate ligament (ACL) injury. (B) Femoral and tibial articulation pressure distribution during simulated ACL injury mechanism as a result of combined valgus and anterior tibial translation. (C) Posterolateral tibial plateau and (D), (E) lateral femoral condyle articular pressure distribution patterns. The sections for the tibia and femur are divided into anterior lateral (AL), middle lateral (ML), posterior lateral $(P L)$, anterior medial $(A M)$, middle medial (MM) and posterior medial (PM). 
Why is there controversy in the literature regarding a "valgus collapse" mechanism?

In a recent review paper, Yu and Garrett ${ }^{18}$ disputed the idea that knee abduction could be associated with isolated ACL injury. They argued that "valgus" cannot cause ACL injuries, because they believe that the ACL is not the major load-bearing structure during valgus loads. Yu and Garrett ${ }^{18}$ also questioned the validity of our prospective coupled biomechanical-epidemiological studies that demonstrated that knee abduction was a strong predictor of future non-contact ACL injury risk in female athletes. However, we did not claim that the ACL injury was caused by a "pure" valgus mechanism. Our experimental analysis demonstrated a strong and clear association between prospectively measured variables, knee abduction motion and torque, and subsequent ACL injuries in female athletes. These observations may be interpreted in different ways, but the statistical and clinical significance of this association is well established in the peer-reviewed literature. Yu and Garrett ${ }^{18}$ may be correct in supporting a primarily "sagittal plane" ACL injury mechanism for male athletes. However, ignoring the increasing evidence for valgus collapse as a mechanism for injury, especially in female athletes, could seriously impede ACL injury intervention efforts if dangerous frontal plane biomechanics are ignored in prediction and prevention programmes.

\section{Are studies of non-weightbearing ACL strain and isolated bundles relevant?}

$\mathrm{Yu}$ and Garrett $^{18}$ suggested that in-vivo arthroscopic ACL strain measurements indicate that passive valgus torques or external tibial rotations do not significantly increase strains in the ACL. ${ }^{50}$ However, weightbearing conditions can significantly increase the ACL strain (2-4\%) during external tibial torques in the range $0-10 \mathrm{Nm}$. As ACL injuries occur during weightbearing conditions, it may be feasible that an external rotation torque could damage the ACL. ${ }^{50}$ Although a passive valgus torque during weightbearing conditions increases ACL strain compared with non-weightbearing conditions, the strain remains relatively constant over a wide range of torques.

It is important to note that the strain in the posteromedial ACL bundle cannot be measured using current arthroscopic techniques. Cadaveric studies indicate that when a valgus load is applied to the knee joint from $0^{\circ}$ to $90^{\circ}$ of knee flexion, the posterolateral ACL bundle shows a nearly fourfold greater change in length compared with the anteromedial bundle. ${ }^{28}$ Therefore, measuring only the anteromedial bundle of the ACL may not appropriately assess the amount of strain that occurs in the total ACL during a valgus load.

\section{Why are not more medial collateral ligament injuries associated with non-contact ACL injuries?}

As $\mathrm{Yu}$ and Garrett $^{18}$ pointed out in their review, clinical observation and epidemiology studies suggest that concomitant $\mathrm{ACL} /$ medial collateral ligament $(\mathrm{MCL})$ injuries are relatively rare and occur in less than $30 \%$ of total ACL injuries. ${ }^{15152}$ Therefore, the valgus motion and torque at the knee joint that are associated with increased ACL injury risk may present a conundrum to clinicians and researchers. The predominance of isolated ACL injury during non-contact mechanisms is a challenge for clinicians to explain. If non-contact ACL injuries occur as a result of valgus collapse of the knee joint, higher combined ACL/MCL injury patterns would be expected, particularly in women.
The ACL and MCL both provide restraint to external valgus. Cadaveric studies show that the ACL appears to restrain knee valgus by limiting axial tibial rotation, whereas the MCL restrains knee valgus by limiting medial joint space opening. ${ }^{53}$ At low flexion angles, ACL deficiency produces greater increases in knee valgus rotation than isolated MCL deficiency. However, medial joint space opening in ACL-deficient knees is relatively small compared with the medial joint space opening in MCLdeficient knees. $^{53}$ Therefore, both the ACL and MCL are important restraints to valgus loads and either one may potentially be injured during high knee valgus loading.

Depending upon the age of the specimen, rate and orientation of loading, ACL failure loads are reported to range from approximately 640 to 2100 Newtons (N) ${ }^{54-56}$ In contrast, cadaveric MCL failure loads have been reported to be as high as $2300 \mathrm{~N}$ for complete MCL disruption. ${ }^{57}$ These disparities in relative failure loads may help to explain why the ACL may fail earlier than the MCL during external valgus loading. In addition, the reported cadaveric failure loads were determined by applying pure distraction to each ligament individually, with loads applied along the fibre lines. During pure valgus loading, the MCL takes stress along its fibre lines, whereas the ACL may be loaded in a suboptimal orientation to handle high stresses. Mommersteeg et $a l^{58}$ found that orientation of loading at the knee is more critical in the cruciate ligaments compared with the collaterals and that loading orientation may affect the tensile stiffness of the ACL. Mommersteeg and colleagues ${ }^{59}$ also showed that collagen density is different between human ACL and MCL, with the ACL showing significantly lower collagen density compared with the MCL. Variations in collagen density have been shown to correspond to differences in Young's modulus for the ACL and MCL. ${ }^{60}$ Therefore, even if the MCL is the primary restraint to an external valgus load, suboptimal orientation loading and collagen property differences may place the ACL at risk of failure before the MCL.

Few studies have examined ACL and MCL loading concurrently during a valgus load, and cross-referencing of studies to determine how the ACL and MCL behave simultaneously is complex due to the variability in laxity between specimens and different testing conditions. Yasuda et $a^{l^{61}}$ demonstrated that during a valgus impact load, the ACL and MCL never elongated simultaneously during impact, and the time to peak elongation in the MCL occurred before the ACL at full extension. In contrast, at $30^{\circ}$ of knee flexion, the ACL reached maximum elongation approximately $16 \mathrm{~ms}$ earlier than the MCL. As ACL injury probably occurs near initial foot contact (within the first 50 ms after contact) with the ground, ${ }^{9}$ a longer time to peak elongation could potentially explain how the ACL becomes at risk before the MCL during a valgus load. Shin et al ${ }^{62}$ conducted a modelling study that found that the MCL may only resist valgus loading effectively after some degree of medial joint opening. Valgus collapse that incorporates transverse plane rotations or that is combined with anterior tibial translations before the medial joint opens enough to strain the MCL may thus also potentially explain how the ACL could tear without MCL injury. ${ }^{22} 48$

Despite the epidemiological evidence that combined ACL/ MCL injuries are relatively less common than isolated injuries, ${ }^{1}{ }^{51} 52$ combined ACL/MCL injuries may be underreported or underdiagnosed. A valgus load sufficient to rupture the ACL may not result in observable injury to the MCL. Cellular damage may occur, but not at a level that may be indicated by clinical examination, imaging or arthroscopy. In direct contrast to most imaging studies examining the incidence of ACL/MCL 
injury, Viskontas et $a{ }^{40}$ reported that $70 \%$ of ACL tears had associated grade 1-3 MCL injuries. The discrepancy between previous reports and the study by Viskontas et $a l^{40}$ may be due to the differences in the methods used to determine MCL injury. Many of the previous studies reporting ACL/MCL injuries did not include grade 1 injuries of the MCL or did not report injury grading schemes. Moreover, many studies relied exclusively on a clinical examination (valgus stress test) to determine injury to the MCL. Grood et a ${ }^{14}$ examined the ability of a valgus stress test to determine the "grade" of MCL injury and found that knees with complete MCL disruption only registered a motion increase of $5.5 \mathrm{~mm}$; which by most clinical grading systems is a borderline grade 2 ligament injury (5$10 \mathrm{~mm})$.

The clinical perception of a relatively low incidence of combined ACL/MCL injuries may be more related to the challenges of diagnosing minor sprains of the MCL compared with the more traumatic disruption of the ACL. ${ }^{63}$ The diagnostic sensitivity of an MRI for determining MCL injury is less than $60 \%$, compared with the relatively high sensitivity $(86 \%)$ and specificity (92\%) for diagnosing an ACL injury. ${ }^{64}$ Whereas complete traumatic midsubstance ruptures of the ACL are common, complete MCL midsubstance disruptions are rare. The majority of diagnosed MCL injuries are partial ligament tears in which the MCL often splinters at the deep femoral or tibial insertions rather than sustaining midsubstance disruption. Moreover, the complex anatomy of the medial and posteromedial structures of the knee joint makes it difficult to determine isolated MCL injury. Previous studies that examined MCL injury have often differed in their description of MCL injury, with regard to the inclusion of superficial MCL, deep MCL structures and/or the posterior oblique ligament, as a result of the difficulty in differentiating between the structures during physical and imaging examinations. ${ }^{65}$ Also, clinicians may not be highly motivated to diagnose an MCL injury, especially a relatively minor sprain, with an ACL rupture because it does not significantly alter the course of treatment. The low reported incidence of combined ACL/MCL injury thus does not necessarily indicate that ACL injuries do not occur as a result of knee valgus collapse.

Cumulatively, and in direct contrast with the assertions of the review by $\mathrm{Yu}$ and Garrett, ${ }^{18}$ this evidence indicates that valgus collapse can potentially lead to non-contact ACL injury. As described above, the knee probably experiences high loading conditions simultaneously in multiple planes, particularly in sporting manoeuvres such as landing, jumping and cutting, all of which require movements in multiple planes. It is thus unlikely that a non-contact ACL injury occurs in a single isolated plane, especially in the female athlete.

\section{SAGITTAL PLANE MECHANISM: UNLIKELY TO BE THE SOLE PLANAR ACL INJURY MECHANISM IN WOMEN}

During sagittal plane movements at the knee joint, anterior shear force at the proximal end of the tibia through the patella tendon can be produced by quadriceps muscle contractions. ${ }^{24} 66$ Anterior shear of the proximal tibia relative to the femur directly loads the ACL, and sagittal plane knee angles near full extension $\left(0-30^{\circ}\right.$ of flexion) increase this anterior tibial shear force. $^{22} 2466{ }^{67}$ Theoretically, a powerful quadriceps force near full knee extension could thus produce enough anterior shear force at the tibia to cause ACL rupture..$^{22} 68$

Cadaveric, diagnostic and in-vivo arthroscopy studies demonstrate that the ACL is a primary restraint to anterior shear loading $^{14} 1622$ and ACL-deficient knees have significantly more anterior tibial translation compared with ACL intact conditions. ${ }^{69} 70$ These findings indicate that a function of the ACL is to prevent sagittal plane translations, and large anterior tibial shear forces could potentially compromise the ACL. However, it is important to consider that most of these studies solely evaluated anterior tibial translation and did not consider other planes in the diagnostic evaluation. Publication biases towards the sagittal plane restraints of the ACL have driven many of the oversimplified assumptions of sagittal plane proponents to ACL injury.

The bone bruise data strongly contradict a solely sagittal plane mechanism of ACL rupture, most especially in women. As described above, bone bruises of the lateral femoral condyle or posterolateral portions of the tibial plateau are common after acute ACL injury, and these bone bruising patterns may indicate that the tibia shifts anteriorly relative to the femur during ACL injury. ${ }^{37-40}$ The slope of the tibial plateau may also contribute to sagittal plane ACL injury mechanisms, as pure compression across a tibial access with $5-15^{\circ}$ of posterior slope could increase anterior tibial translation and ACL strain. ${ }^{46}$ Brandon et al ${ }^{46}$ found an association between increased posterior tibial slope and ACL injury. However, if the injury mechanism was solely as a result of anterior tibial shear, the bone bruise patterns on MRI after ACL injury would most likely be located along the medial tibial plateau as well as the lateral tibial plateau. As the bone bruises are most often located laterally, in addition to the posterior tibial pattern, lateral compression and valgus probably occur during these ACL injuries.

The relationship between the knee flexion angle and the potential for ACL injury has also been explored extensively in the literature. Interview and video studies indicate that ACL injury usually occurs at shallow $\left(0-30^{\circ}\right)$ knee flexion angles. ${ }^{9-}$ 12217172 Cadaveric studies show that the knee joint has the potential to translate more in the sagittal plane during shallow knee flexion angles, and anterior tibial shear forces generate the greatest ACL loads during $20-40^{\circ}$ of knee flexion. ${ }^{22} 6973$ At the same time, women have been suggested to have shallow knee flexion angles during landing, jumping and cutting tasks compared with men. ${ }^{317475}$ However, other studies show no sex difference or even greater knee flexion in women during athletic tasks. ${ }^{307677}$ Furthermore, the knee flexion angle at landing does not appear to predict ACL injury risk, ${ }^{20}$ and videos of ACL injuries indicate that women may have similar or even greater knee flexion angles than men during the injury event. ${ }^{9} 10$

Many sports manoeuvres induce large quadriceps forces at relatively shallow knee flexion angles, which may increase anterior tibial shear and ACL strain..$^{24}{ }^{78-83}$ Isolated quadriceps contractions increase ACL strain and force during shallow knee flexion angles, ${ }^{79}{ }^{81-83}$ and electromyographic studies show that women have significant neuromuscular imbalances between quadriceps and hamstrings recruitment, which create difficulty for deceleration from a landing and control of anterior tibial translation. ${ }^{84}{ }^{85}$ Withrow et $a^{166}$ showed that ACL strain is proportional to increased quadriceps forces during high impact loads. Strong quadriceps contraction can produce anterior tibial translation great enough to injure the ACL during shallow knee flexion angles. ${ }^{24}{ }^{87}$ When a $4500 \mathrm{~N}$ quadriceps force was applied to cadaveric specimens, six of the 11 specimens sustained a partial or complete ACL rupture. ${ }^{24}$ However, quadriceps contraction appeared to affect ACL loading in more than one plane of motion, with knee internal rotation and valgus moments occurring coincident with anterior tibial translation. ${ }^{24}$ Cadaveric and mathematical modelling studies indicate that hamstrings co-contraction with quadriceps contraction can lead 
to joint compression, decrease anterior tibial translation and effectively reduce excessive forces in the ACL, particularly between $15^{\circ}$ and $60^{\circ}$ of knee flexion. ${ }^{6688} 89$

Shin et a ${ }^{90}$ reported that large ground reaction forces directed posterior relative to the proximal tibia help protect the ACL during landing from a jump and during a run-to-stop simulation. Moreover, several mathematical models have demonstrated that sagittal plane mechanisms alone cannot account for ACL forces high enough to rupture the ACL. ${ }^{33} 91$ McLean and colleagues $^{32-34}$ used forward dynamic musculoskeletal models to simulate random perturbations during cutting movements and found that peak anterior drawer forces never led to ACL forces high enough to cause ACL injury. Therefore, despite the evidence that sagittal plane mechanics can cause large ACL loads, it is highly unlikely that non-contact ACL injuries result exclusively from a sagittal plane mechanism (especially in the female athlete).

\section{ACL INJURY PREVENTION PROGRAMMES}

There is increasing evidence that neuromuscular training programmes can reduce the risk of ACL injury. These programmes have included plyometric, biomechanical analysis and technique feedback, proprioceptive/balance and strength training in various combinations. ${ }^{2}{ }^{92-94}$ However, which types of interventions and which biomechanical risk factors should be targeted to reduce ACL injury risk most effectively remains a topic of debate. Prevention and intervention programmes that only target high-risk sagittal plane biomechanics such as shallow knee flexion angles, large distal tibia posterior ground reaction forces and large quadriceps muscle forces may not address other underlying risk factors in the frontal and transverse planes. ${ }^{95} 96$ Failing to incorporate rotational, multidirectional training exercises during training programmes may hamper ACL injury prevention efforts.

We hypothesise that non-contact ACL injury results from multiplanar knee joint loading during three-dimensional sports movements, encompassed by more than simply anterior shear. The load sharing between knee ligaments is complex and it seems plausible that anterior tibial shear force and axial rotation torque also contribute to the resultant ACL loading during the "valgus" collapse of the knee so often observed during injury, especially in female athletes.

\section{What is already known on this topic}

ACL injury is a common problem in young athletes. Identification of risk factors and the development of ACL prevention programmes may help decrease injury risk. Although studies indicate that sagittal plane biomechanical factors contribute to ACL loading mechanisms, it is unlikely that non-contact ACL injuries occur solely in a sagittal plane.

\section{What this study adds}

The purpose of this review is to summarise existing evidence about ACL injury mechanisms and to propose that sex-specific mechanisms of ACL injury may occur, with women sustaining injuries predominantly as a result of a "valgus collapse" mechanism.

\section{SUMMARY AND CONCLUSIONS}

In summary, the load sharing between knee ligaments is complex. Frontal plane "valgus collapse", as well as sagittal and transverse plane biomechanical factors, likely contribute to ACL injury events. Non-contact ACL injuries almost certainly occur during complex, multiplanar knee joint load states during multiplanar sports movements, rather than during single sagittal planar mechanisms of injury. Although studies indicate that sagittal plane biomechanical factors are probably a part of the ACL loading mechanism, it is highly doubtful that these injuries occur solely as a result of sagittal plane loading mechanisms, especially in the female athlete. Prevention programmes that solely target high-risk sagittal plane landing mechanics fail to address the important frontal and transverse plane contributions to ACL injury mechanisms. Multiplanar training exercises that focus on lowering risky biomechanics in multiple planes such as large knee valgus, internal/external knee rotations and shallow knee flexion angles are needed to minimise hazardous knee loading conditions that cause ACL injury.

Acknowledgements: The authors would like to thank the staff at the Cincinnati Children's Hospital Sports Medicine Biodynamics Center for the many thoughtful, and sometimes raucous, discussions pertaining to this topic.

Funding: The authors would like to acknowledge funding support from the University of Toledo College of Medicine Pre-Doctoral Fellowship and the Plus One Active Research Grant on Wellness Using Internet Technology from the American College of Sports Medicine Foundation (CEO). This work was also partly supported by National Institutes of Health grants R01-AR049735 and R01-AR055563 (TEH) and R01AR056259 (CEO and TEH).

Competing interests: None.

\section{REFERENCES}

1. Miyaska KC, Daniel DM, Stone ML, et al. The incidence of knee ligament injuries in the general population. Am J Knee Surg 1991;4:3-7.

2. Hewett TE, Lindenfeld TN, Riccobene JV, et al. The effect of neuromuscular training on the incidence of knee injury in female athletes. A prospective study. Am J Sports Med 1999;27:699-706.

3. Gillquist J, Messner K. Anterior cruciate ligament reconstruction and the long-term incidence of gonarthrosis. Sports Med 1999;27:143-56.

4. Myklebust G, Bahr R. Return to play guidelines after anterior cruciate ligament surgery. Br J Sports Med 2005;39:127-31.

5. von Porat A, Roos EM, Roos H. High prevalence of osteoarthritis 14 years after an anterior cruciate ligament tear in male soccer players: a study of radiographic and patient relevant outcomes. Ann Rheum Dis 2004;63:269-73.

6. Agel J, Arendt EA, Bershadsky B. Anterior cruciate ligament injury in national collegiate athletic association basketball and soccer: a 13-year review. Am J Sports Med 2005;33:524-30.

7. Arendt E, Dick R. Knee injury patterns among men and women in collegiate basketball and soccer. NCAA data and review of literature. Am J Sports Med 1995;23:694-701.

8. Hewett TE, Ford KR, Myer GD. Anterior cruciate ligament injuries in female athletes. Part 2: A meta-analysis of neuromuscular interventions aimed at injury prevention. Am J Sports Med 2006;34:490-8.

9. Krosshaug T, Nakamae A, Boden BP, et al. Mechanisms of anterior cruciate ligament injury in basketball: video analysis of 39 cases. Am J Sports Med 2007;35:359-67.

10. Boden BP, Torg JS, Knowles SB, et al. Video analysis of anterior cruciate ligament injury: abnormalities in hip and ankle kinematics. Am J Sports Med 2009;37:252-9.

11. Boden BP, Dean GS, Feagin JA, et al. Mechanisms of anterior cruciate ligament injury. Orthopedics 2000;23:573-8.

12. Cochrane JL, Lloyd DG, Buttfield A, et al. Characteristics of anterior cruciate ligament injuries in Australian football. J Sci Med Sport 2007;10:96-104.

13. Lightfoot AJ, McKinley T, Doyle M, et al. ACL tears in collegiate wrestlers: report of six cases in one season. lowa Orthop $J$ 2005;25:145-8.

14. Grood ES, Noyes FR, Butler DL, et al. Ligamentous and capsular restraints preventing straight medial and lateral laxity in intact human cadaver knees. J Bone Joint Surg Am 1981;63:1257-69.

15. Butler DL, Noyes FR, Grood ES. Ligamentous restraints to anterior-posterior drawer in the human knee. A biomechanical study. J Bone Joint Surg Am 1980;62:259-70.

16. Markolf KL, Mensch JS, Amstutz HC. Stiffness and laxity of the knee-the contributions of the supporting structures. A quantitative in vitro study. J Bone Joint Surg Am 1976;58:583-94. 
17. Markolf KL, Graff-Redford A, Amstutz HC. In vivo knee stability: a quantitative assessment using an instrumented clinical testing apparatus. J Bone Joint Surg 1978;60-A:664-74

18. Yu B, Garrett WE. Mechanisms of non-contact ACL injuries. Br J Sports Med 2007; 41(Suppl 1):i47-51.

19. Woo SL, Gomez MA, Seguchi Y, et al. Measurement of mechanical properties of ligament substance from a bone-ligament-bone preparation. J Orthop Res 1983;1:22-9.

20. Hewett TE, Myer GD, Ford KR, et al. Biomechanical measures of neuromuscular control and valgus loading of the knee predict anterior cruciate ligament injury risk in female athletes: a prospective study. Am J Sports Med 2005;33:492-501.

21. Olsen $\mathbf{0 E}$, Myklebust $\mathrm{G}$, Engebretsen $\mathrm{L}$, et al. Injury mechanisms for anterior cruciate ligament injuries in team handball: a systematic video analysis. Am J Sports Med 2004;32:1002-12.

22. Markolf KL, Burchfield DM, Shapiro MM, et al. Combined knee loading states that generate high anterior cruciate ligament forces. J Orthop Res 1995;13:930-5.

23. Butler DL, Grood ES, Noyes FR, et al. Mechanical properties of primate vascularized vs. nonvascularized patellar tendon grafts; changes over time. J Orthop Res 1989;7:68-79.

24. DeMorat G, Weinhold P, Blackburn T, et al. Aggressive quadriceps loading can induce noncontact anterior cruciate ligament injury. Am J Sports Med 2004:32:47783.

25. Ahmed AM, Burke DL, Duncan NA, et al. Ligament tension pattern in the flexed knee in combined passive anterior translation and axial rotation. J Orthop Res 1992;10:854-67

26. Wascher DC, Markolf KL, Shapiro MS, et al. Direct in vitro measurement of forces in the cruciate ligaments. Part I: The effect of multiplane loading in the intact knee. J Bone Joint Surg Am 1993;75:377-86.

27. Kanamori A, Woo SL, Ma CB, et al. The forces in the anterior cruciate ligament and knee kinematics during a simulated pivot shift test: a human cadaveric study using robotic technology. Arthroscopy 2000;16:633-9.

28. Hollis JM, Takai S, Adams DJ, et al. The effects of knee motion and external loading on the length of the anterior cruciate ligament $(\mathrm{ACL})$ : a kinematic study. J Biomech Eng 1991;113:208-14.

29. Hewett TE, Myer GD, Ford KR. Decrease in neuromuscular control about the knee with maturation in female athletes. J Bone Joint Surg Am 2004;86-A:1601-8.

30. Ford KR, Myer GD, Toms HE, et al. Gender differences in the kinematics of unanticipated cutting in young athletes. Med Sci Sports 2005;37:124-9.

31. Malinzak RA, Colby SM, Kirkendall DT, et al. A comparison of knee joint motion patterns between men and women in selected athletic tasks. Clin Biomech 2001;16:438-45

32. McLean SG, Neal RJ, Myers PT, et al. Knee joint kinematics during the sidestep cutting maneuver: potential for injury in women. Med Sci Sports Exerc 1999;31:95968.

33. McLean SG, Huang $X$, Su A, et al. Sagittal plane biomechanics cannot injure the ACL during sidestep cutting. Clin Biomech 2004;19:828-38.

34. McLean SG, Huang $X$, van den Bogert AJ. Investigating isolated neuromuscular control contributions to non-contact anterior cruciate ligament injury risk via computer simulation methods. Clin Biomech (Bristol, Avon) 2008;23:926-36.

35. Benjaminse A, Gokeler A, van der Schans CP. Clinical diagnosis of an anterior cruciate ligament rupture: a meta-analysis. J Orthop Sports Phys Ther 2006;36:26788.

36. Kostogiannis I, Ageberg E, Neuman P, et al. Clinically assessed knee joint laxity as a predictor for reconstruction after an anterior cruciate ligament injury: a prospective study of 100 patients treated with activity modification and rehabilitation. Am J Sports Med 2008:36:1528-33.

37. Mink JH, Deutsch AL. Occult cartilage and bone injuries of the knee: detection classification, and assessment with MR imaging. Radiology 1989;170:823-9.

38. Kaplan PA, Walker CW, Kilcoyne RF, et al. Occult fracture patterns of the knee associated with anterior cruciate ligament tears: assessment with MR imaging. Radiology 1992:183:835-8.

39. Sanders TG, Medynski MA, Feller JF, et al. Bone contusion patterns of the knee at MR imaging: footprint of the mechanism of injury. Radiographics 2000;20:S135-51.

40. Viskontas DG, Giuffre BM, Duggal N, et al. Bone bruises associated with ACL rupture: correlation with injury mechanism. Am J Sports Med 2008;36:927-33.

41. Fayad LM, Parellada JA, Parker L, et al. MR imaging of anterior cruciate ligament tears: is there a gender gap? Skeletal Radiol 2003;32:639-46.

42. Ford KR, Myer GD, Divine JG, et al. Landing differences in high school female soccer players grouped by age. Med Sci Sports Exerc 2004;36:S293.

43. Kernozek TW, Torry MR, H VH, et al. Gender differences in frontal and sagittal plane biomechanics during drop landings. Med Sci Sports Exerc 2005;37:1003-12; discussion 13.

44. Stijak L, Herzog RF, Schai P. Is there an influence of the tibial slope of the lateral condyle on the ACL lesion? A case-control study. Knee Surg Sports Traumatol Arthrosc 2008:16:112-17.

45. Kujala UM, Nelimarkka 0, Koskinen SK. Relationship between the pivot shift and the configuration of the lateral tibial plateau. Arch Orthop Trauma Surg 1992:111:228-9.

46. Brandon ML, Haynes PT, Bonamo JR, et al. The association between posteriorinferior tibial slope and anterior cruciate ligament insufficiency. Arthroscopy 2006;22:894-9.

47. Mahfouz MR, Komistek RD, Dennis DA, et al. In vivo assessment of the kinematics in normal and anterior cruciate ligament-deficient knees. J Bone Joint Surg Am 2004:86-A(Suppl 2):56-61.
48. Berns GS, Hull ML, Patterson HA. Strain in the anteromedial bundle of the anterior cruciate ligament under combination loading. J Orthop Res 1992:10:167-76.

49. Withrow TJ, Huston LJ, Wojtys EM, et al. The effect of an impulsive knee valgus moment on in vitro relative $\mathrm{ACL}$ strain during a simulated jump landing. Clin Biomech (Bristol, Avon) 2006;21:977-83.

50. Fleming BC, Renstrom PA, Beynnon BD, et al. The effect of weightbearing and external loading on anterior cruicate ligament strain. J Biomech 2001;34:163-70.

51. LaPrade RF, Wentorf FA, Fritts $\mathrm{H}$, et al. A prospective magnetic resonance imaging study of the incidence of posterolateral and multiple ligament injuries in acute knee injuries presenting with a hemarthrosis. Arthroscopy 2007:23:1341-7.

52. Majewski M, Susanne H, Klaus S. Epidemiology of athletic knee injuries: a 10-year study. Knee 2006;13:184-8.

53. Matsumoto $\mathbf{H}$, Suda Y, Otani T, et al. Roles of the anterior cruciate ligament and the medial collateral ligament in preventing valgus instability. J Orthop Sci 2001;6:28-32.

54. Kennedy JC, Hawkins RJ, Willis RB, et al. Tension studies of human knee ligaments. Yield point, ultimate failure, and disruption of the cruciate and tibial collateral ligaments. J Bone Joint Surg Am 1976;58:350-5.

55. Trent PS, Walker PS, Wolf B. Ligament length patterns, strength, and rotational axes of the knee joint. Clin Orthop Relat Res 1976;117:263-70.

56. Woo SL, Hollis JM, Adams DJ, et al. Tensile properties of the human femur-anterior cruciate ligament-tibia complex: the effects of specimen age and orientation. Am J Sport Med 1991;19:217-27.

57. Paulos LE, France EP, Rosenberg TD, et al. The biomechanics of lateral knee bracing Part I: Response of the valgus restraints to loading. Am J Sports Med 1987;15:41929.

58. Momersteeg TJ, Blankevoort $\mathrm{L}$, Huiskes $\mathrm{R}$, et al. The effect of variable relative insertion orientation of human knee bone-ligament-bone complexes on the tensile stiffness. J Biomech 1995:28:745-52

59. Mommersteeg TJ, Blankevoort L, Kooloos JG, et al. Nonuniform distribution of collagen density in human knee ligaments. J Orthop Res 1994;12:238-45.

60. Woo SL, Newton PO, MacKenna DA, et al. A comparative evaluation of the mechanical properties of the rabbit medial collateral and anterior cruciate ligaments. J Biomech 1992;25:377-86.

61. Yasuda K, Erickson AR, Beynnon BD, et al. Dynamic elongation behavior in the medial collateral and anterior cruciate ligaments during lateral impact loading. J Orthop Res 1993;11:190-8.

62. Shin CS, Chaudhari AM, Andriacchi TP. The effect of isolated valgus moments on ACL strain during single-leg landing: a simulation study. J Biomech 2009;42:280-5.

63. Munshi M, Pretterklieber ML, Kwak S, et al. MR imaging, MR arthrography, and specimen correlation of the posterolateral corner of the knee: an anatomic study. AJR Am J Roentgenol 2003;180:1095-101.

64. Lundberg $\mathbf{M}$, Odensten M, Thuomas KA et al. The diagnostic validity of magnetic resonance imaging in acute knee injuries with hemarthrosis. A single-blinded evaluation in 69 patients using high-field MRI before arthroscopy. Int J Sports Med 1996:17:218-22.

65. Jacobson KE, Chi FS. Evaluation and treatment of medial collateral ligament and medial-sided injuries of the knee. Sports Med Arthrosc 2006:14:58-66.

66. Li G, Gil J, Kanamori A, et al. A validated three-dimensional computational model of a human knee joint. J Biomech Eng 1999;121:657-62.

67. Sell TC, Ferris CM, Abt JP, et al. Predictors of proximal tibia anterior shear force during a vertical stop-jump. J Orthop Res 2007;25:1589-97.

68. Kirkendall DT, Garrett WE Jr. The anterior cruciate ligament enigma. Injury mechanisms and prevention. Clin Orthop 2000:372:64-8.

69. Daniel DM, Malcom LL, Losse G, et al. Instrumented measurement of anterior laxity of the knee. J Bone Joint Surg 1985;67A:720-6.

70. Logan MC, Williams A, Lavelle J, et al. What really happens during the Lachman test? A dynamic MRI analysis of tibiofemoral motion [correction appears in Am J Sports Med 2004:32:824]. Am J Sports Med 2004:32:369-75.

71. Ferretti A, Papandrea P, Conteduca F, et al. Knee ligament injuries in volleyball players. Am J Sports Med 1992;20:203-7.

72. McNair PJ, Marshall RN, Matheson JA. Important features associated with acute anterior cruciate ligament injury. N Z Med J 1990;103:537-9.

73. Fukubayashi T, Torzilli PA, Sherman MF, et al. An in vitro biomechanical evaluation of anterior-posterior motion of the knee. Tibial displacement, rotation, and torque. J Bone Joint Surg Am 1982;64:258-64.

74. Chappell JD, Yu B, Kirkendall DT, et al. A comparison of knee kinetics between male and female recreational athletes in stop-jump tasks. Am J Sports Med 2002;30 $261-7$

75. Huston LJ, Vibert B, Ashton-Miller JA, et al. Gender differences in knee angle when landing from a drop-jump. Am J Knee Surg 2001;14:215-19; discussion 9-20.

76. Fagenbaum R, Darling WG. Jump landing strategies in male and female college athletes and the implications of such strategies for anterior cruciate ligament injury. Am J Sports Med 2003;31:233-40.

77. Pollard CD, Davis IM, Hamill J. Influence of gender on hip and knee mechanics during a randomly cued cutting maneuver. Clin Biomech 2004;19:1022-31.

78. Durselen L, Claes L, Kiefer H. The influence of muscle forces and external loads on cruciate ligament strain. Am J Sports Med 1995:23:129-36.

79. Arms SW, Pope MH, Johnson RJ, et al. The biomechanics of anterior cruciate ligament rehabilitation and reconstruction. Am J Sports Med 1984;12:8-18.

80. Beynnon BD, Fleming BC, Johnson RJ, et al. Anterior cruciate ligament strain behavior during rehabilitation exercises in vivo. Am J Sports Med 1995;23:24-34.

81. Draganich LF, Vahey JW. An in vitro study of anterior cruciate ligament strain induced by quadriceps and hamstrings forces. J Orthop Res 1990:8:57-63. 
82. Markolf KL, O'Neill G, Jackson SR, et al. Effects of applied quadriceps and hamstrings muscle loads on forces in the anterior and posterior cruciate ligaments. Am J Sports Med 2004;32:1144-9.

83. Renstrom P, Arms SW, Stanwyck TS, et al. Strain within the anterior cruciate ligament during hamstring and quadriceps activity. Am J Sports Med 1986;14:83-7.

84. Chappell JD, Creighton RA, Giuliani C, et al. Kinematics and electromyography of landing preparation in vertical stop-jump: risks for noncontact anterior cruciate ligament injury. Am J Sports Med 2007;35:235-41.

85. Sell TC, Ferris CM, Abt JP, et al. The effect of direction and reaction on the neuromuscular and biomechanical characteristics of the knee during tasks that simulate the noncontact anterior cruciate ligament injury mechanism. Am J Sports Med 2006;34:43-54.

86. Withrow TJ, Huston LJ, Wojtys EM, et al. The relationship between quadriceps muscle force, knee flexion, and anterior cruciate ligament strain in an in vitro simulated jump landing. Am J Sports Med 2006;34:269-74.

87. Pandy MG, Shelburne KB. Dependence of cruciate-ligament loading on muscle forces and external load. J Biomech 1997;30:1015-24.

88. Imran A, O'Connor JJ. Theoretical estimates of cruciate ligament forces: effects of tibial surface geometry and ligament orientations. Proc Inst Mech Eng [H] 1997;211:425-39.
89. Mesfar W, Shirazi-Adl A. Knee joint mechanics under quadriceps-hamstrings muscle forces are influenced by tibial restraint. Clin Biomech (Bristol, Avon) 2006;21:841-8

90. Shin CS, Chaudhari AM, Andriacchi TP. The influence of deceleration forces on $\mathrm{ACL}$ strain during single-leg landing: a simulation study. J Biomech 2007;40:1145-52.

91. Pflum MA, Shelburne KB, Torry MR, et al. Model prediction of anterior cruciate ligament force during drop-landings. Med Sci Sports Exerc 2004;36:1949-58.

92. Myklebust G, Engebretsen L, Braekken IH, et al. Prevention of anterior cruciate ligament injuries in female team handball players: a prospective intervention study over three seasons. Clin J Sport Med 2003;13:71-8.

93. Mandelbaum BR, Silvers HJ, Watanabe D, et al. Effectiveness of a neuromuscular and proprioceptive training program in preventing the incidence of $A C L$ injuries in female athletes: two-year follow up. Am J Sport Med 2005;33:1003-10.

94. Heidt RS Jr, Sweeterman LM, Carlonas RL, et al. Avoidance of soccer injuries with preseason conditioning. Am J Sports Med 2000:28:659-62.

95. Yu B, Herman D, Preston J, et al. Immediate effects of a knee brace with a constraint to knee extension on knee kinematics and ground reaction forces in a stop-jump task. Am J Sports Med 2004;32:1136-43.

96. Lin CF, Liu H, Garrett WE, et al. Effects of a knee extension constraint brace on selected lower extremity motion patterns during a stop-jump task. J App/ Biomech 2008;24:158-65. 